\title{
SISTEMA DE GESTÃO DE ENERGIA: UMA ABORDAGEM SISTEMÁTICA PARA A MELHORIA CONTÍNUA DO DESEMPENHO ENERGÉTICO DA INDÚSTRIA DE METAIS*
}

Gabriel Lenna do Nascimento ${ }^{1}$ Cibele Dmitrijevas ${ }^{2}$

\section{Resumo}

O objetivo deste trabalho é apresentar uma sistemática para a melhoria contínua do desempenho energético da Indústria de Metais. Trata-se de uma abordagem apoiada na norma ISO 50001 e em uma plataforma de TI e Automação chamada Energy Management System (EMS). A plataforma EMS se baseia na norma com o propósito de permitir que organizações definam processos para a melhoria do seu desempenho energético. O trabalho visa também apresentar o grau de aderência entre a norma e a plataforma EMS, assim como os principais ganhos a serem obtidos pelas empresas com a adoção da solução EMS.

Palavras-chave: Gestão de energia; Sistema de gestão de energia; ISO 50001.

\section{ENERGY MANAGEMENT SYSTEM: A SYSTEMATIC APPROACH FOR THE CONTINUOUS IMPROVEMENT OF ENERGY PERFORMANCE IN THE METALS INDUSTRY}

\section{Abstract}

The goal of this paper is to present a systematic approach for continuous improvement of energy performance in the Metals Industry. The approach is based on ISO 50001 and the Energy Management System (EMS), an automation and industrial IT platform. This approach allows organizations to define processes and measures for improvement of energy performance. This paper also shows the adherence between the EMS platform with ISO 50001.

Keywords: Energy management; Energy management system; ISO 50001.

1 Engenheiro de Controle e Automação, MBA em Gestão de Negócios, Gerente Geral de Engenharia e Qualidade da Primetals Technologies, Belo Horizonte, MG, Brasil.

2 Química Industrial, MBA em Gestão e Tecnologias Ambientais (USP), Mestre (IPEN - USP) em Ecoeficiência, Auditora Líder (ISO 9001, ISO 14001, ISO 50001 e OHSAS 18001), auditora SA 8000, Tutora de formação de Auditor Líder e Instrutora de Treinamentos na TÜV Rheinland do Brasil, São Paulo, SP, Brasil. 


\section{INTRODUÇÃO}

Tendências globais como mudanças climáticas, crescente emissão de gases de efeito estufa, processos de urbanização e o crescimento da população têm causado pressões por uma maior eficiência energética e uma maior proteção do meio ambiente. Aqui no Brasil, além destas tendências, questões relacionadas aos crescentes custos de energia e a dificuldade da nossa indústria em competir no mercado internacional trouxeram o tema da eficiência energética novamente para o centro das atenções como possível saída para estes problemas. Em função deste cenário a Primetals Technologies tem investido em soluções de apoio a gestão energética. O EMS (Energy Management System) é uma plataforma de TI Industrial e Automação baseada na norma ISO 50001 e que tem como principal objetivo apoiar na implementação, manutenção e melhoria de sistemas de gestão de energia de forma sistemática e continua visando à melhoria do desempenho energético da Indústria de Metais.

A solução tem seu foco nos seguintes objetivos principais:

- Permitir a redução de custos de energia da Indústria de Metais (Aproximadamente $25 \%$ dos custos de produção estão relacionados ao consumo de energia).

- Permitir as Indústrias de Metais cumprirem com obrigações legais relacionadas ao meio ambiente e se adequarem a norma ISO 50001.

- Apoiar as Indústrias de Metais no desenvolvimento de uma imagem relacionada à sustentabilidade e ambientalmente responsável.

- Aproveitar casos de sucesso de outros segmentos da indústria e adaptá-los aos requisitos da Indústria de Metais.

\section{MATERIAIS E MÉTODOS}

\subsection{Principais aspectos da Norma ISO 50001}

A norma ISO 50001 ou ABNT NBR ISO 50001 foi publicada em Junho de 2011, ou seja, é uma norma relativamente recente e que tem como principal propósito, permitir a definição de uma sistemática de melhoria continua do desempenho energético nas organizações. Com a aplicação global da norma espera-se uma maior disponibilidade do suprimento de energia, a melhoria da competitividade das organizações e um impacto positivo para o meio ambiente. 


\subsection{Estrutura Geral da ISO 50001}

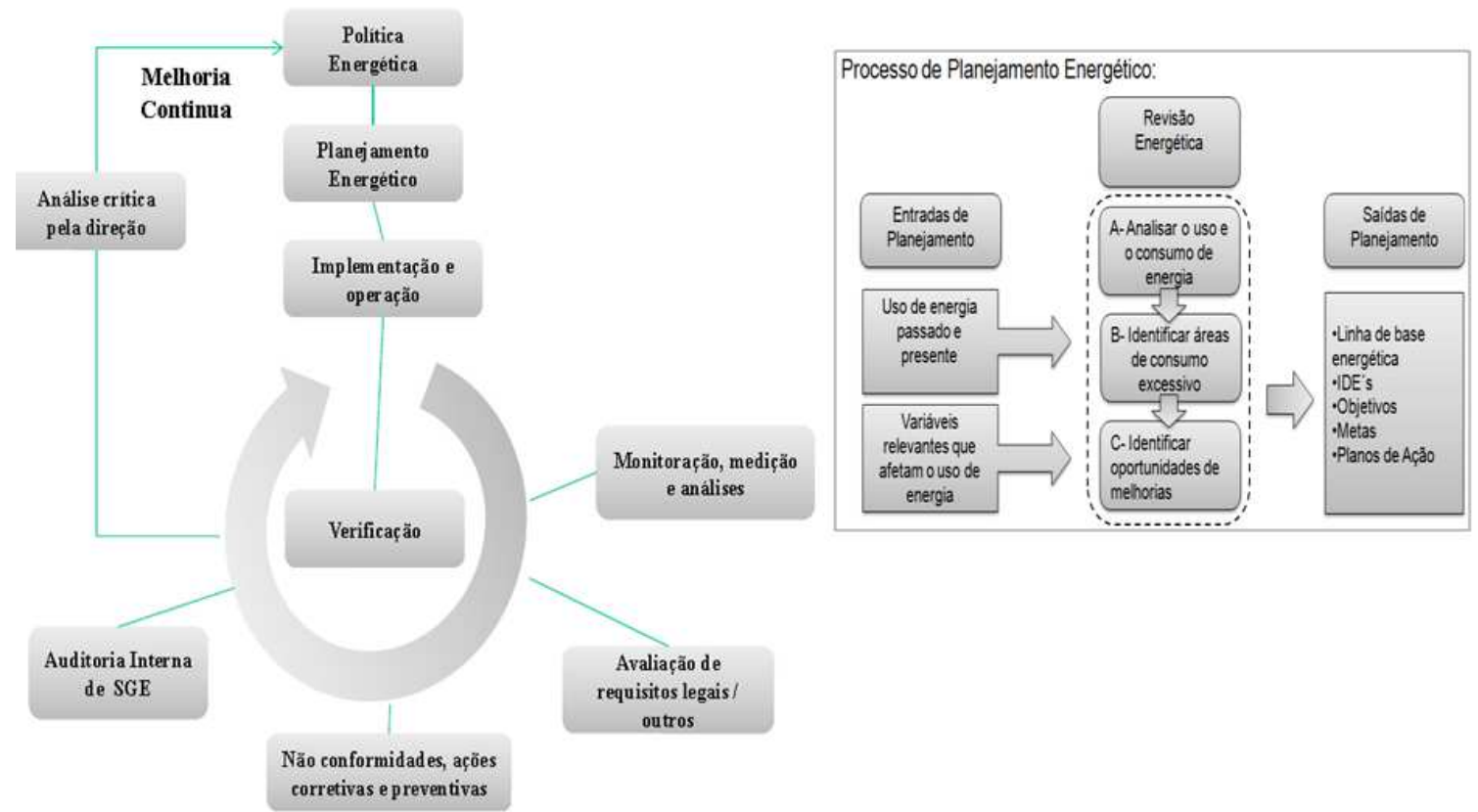

Figura 1 - Estrutura Geral da ISO50001.

A forma como a norma foi estruturada é bastante similar à metodologia PDCA (Plan, Do, Check, Act). Este formato de estrutura permite as organizações estabelecerem uma sistemática que relacionam os aspectos de monitoração, medição e análises de consumo com os níveis de planejamento e as informações de uso e consumo provenientes do chão de fábrica que precisam ser gerenciadas. Este é o primeiro elo entre a norma e a necessidade de uma plataforma de TI e Automação como o EMS para facilitar o processo de gestão energética.

Segue abaixo uma lista dos principais requisitos da norma e que foram utilizados como base para o desenvolvimento da plataforma EMS:

- A necessidade de definição de uma Política Energética direcionadora a implementação das melhorias do SGE (sistema de gestão energética) e do desempenho energético da organização no contexto de seu escopo e fronteiras.

- O estabelecimento de um processo de Planejamento Energético, levando em consideração um plano de ação e a utilização de ferramentas para melhorar continuamente o desempenho energético.

- Desenvolver e manter uma revisão energética. É importante que por meio do processo de identificação e avaliação do uso de energia possam ser identificadas oportunidades de melhoria para o desempenho energético dentro da organização.

- Definir uma linha de base energética: A linha de base energética é mantida como recurso da organização para determinar o período de manutenção dos registros levando em considerações variáveis que afetem o uso e o consumo de energia. Como por exemplo o clima, ciclos de atividades de negócios e outras condições.

- Dispor de indicadores de desempenho energético para a definição de metas e base para monitoramento do desempenho energético.

- Definição de objetivos energéticos, metas energéticas e planos de ação para a gestão de energia. 
- Aquisição de serviços de energia, produtos e equipamentos com o foco na melhoria do desempenho energético.

- Estabelecimento de um processo de verificação, através de monitoramento, medição e análise da performance energética para a constante avaliação do atendimento das metas e do planejamento energético estabelecido. A partir desta verificação é necessário identificar não conformidades e implementar ações corretivas e preventivas.

- Conduzir auditorias com o objetivo de verificar a conformidade do sistema de gestão energética.

- Realizar análise crítica do sistema de gestão energética com comprometimento da alta direção para a definição de metas estratégicas e continuidade do ciclo de melhoria contínua.

Conforme já introduzido, a plataforma EMS visa facilitar a implementação da norma e apoiar de forma sistemática o processo de melhoria contínua de desempenho energético. A plataforma EMS da Primetals utiliza como base o produto SIMATIC B.Data da Siemens e tem customizações específicas para a Indústria de Metais. A seguir apresentamos uma visão geral dos módulos da plataforma EMS para atendimento aos requisitos da norma ISO 50001:

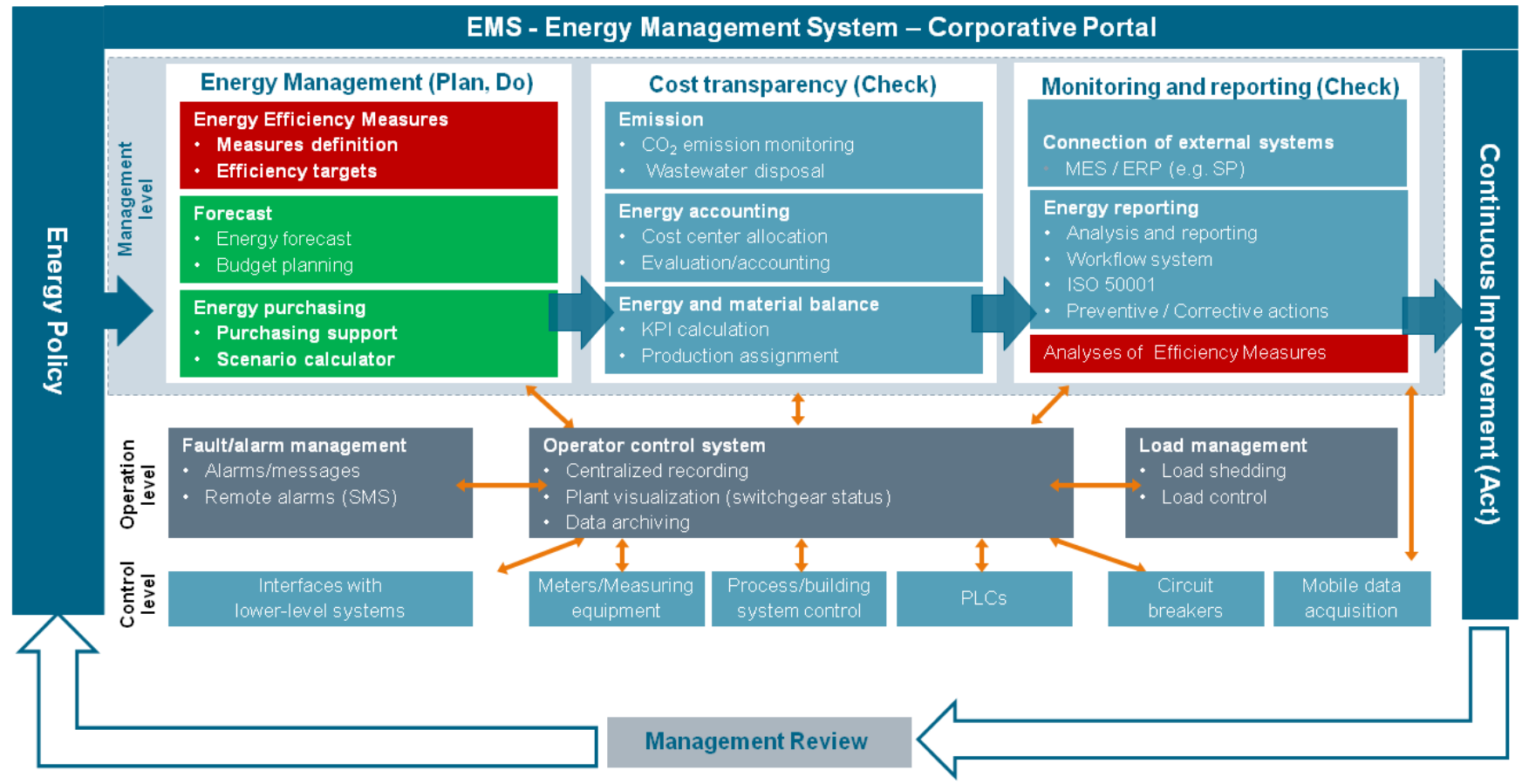

Figura 2 - Visão Geral dos Módulos SEM.

\subsection{Visão Geral dos Modulos EMS}

Os módulos do sistema EMS são basicamente formados por funções de planejamento, verificação/monitoramento e relatórios. Os módulos foram construídos de forma a permitir o fechamento de um ciclo completo de melhoria contínua.

- Funções de Planejamento Energético:

Analisar o uso e o consumo de energia: Falar de consumo de energia não é somente falar de energia elétrica, temos que considerar outras variáveis como energia térmica, combustível, ar pressurizado, gases (Ni, Ar e ect.), água e utilidades em geral, ou seja, as fontes que fazem parte do consumo total das 
plantas. A energia também não é somente consumida através das rotas principais de processo. Áreas como tratamento de água, resfriamento, produção de coke, sinterização e produção de oxigênio também precisam ter seus consumos monitorados e controlados. Para uma melhor avaliação dos consumos é necessário dispor de uma visão holística com relação aos fluxos de consumo de energia.

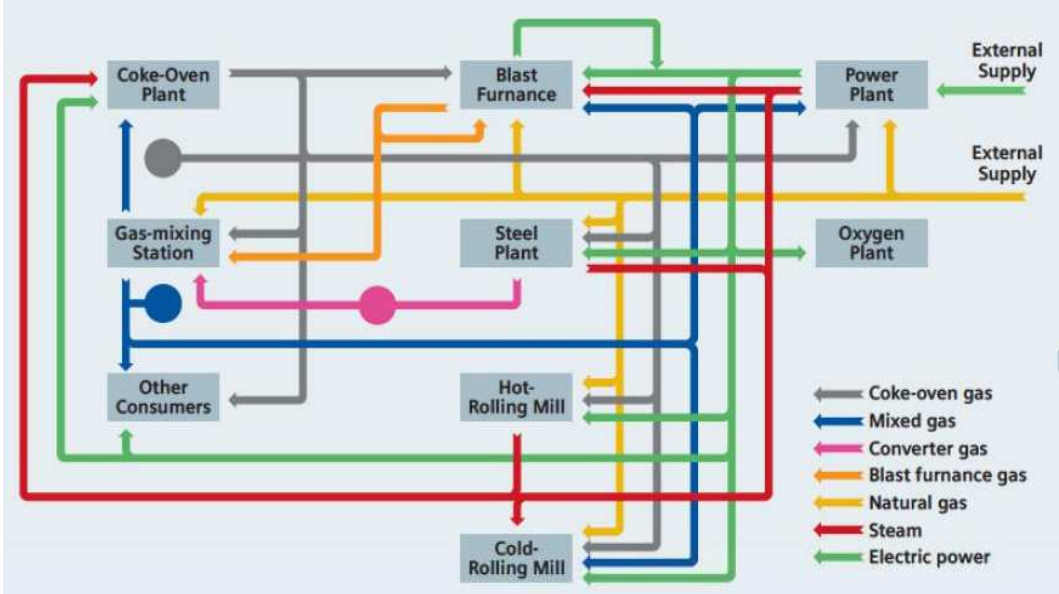

Figura 3 - Visão holística dos fluxos de energia.

Identificar áreas de consumo excessivo e oportunidades de melhoria: A fim de garantir o atendimento ao requisito da norma referente à "Revisão Energética", a ferramenta permite o mapeamento do fluxo de energia em cada um dos equipamentos da planta, e possibilita a identificação dos maiores consumidores, áreas com potencial para a redução de energia, assim como a definição de ações, planos e metas para economia de energia no processo. Com um mapeamento mais detalhado dos processos é possível conhecer as interdependências entre os processos e passar a propor ações capazes de trazer economia de energia para o sistema como um todo. Em função do que se planeja produzir o módulo de gestão de energia permite a criação de cenários de consumo e a definição de budget para as despesas com energia de uma forma periódica.
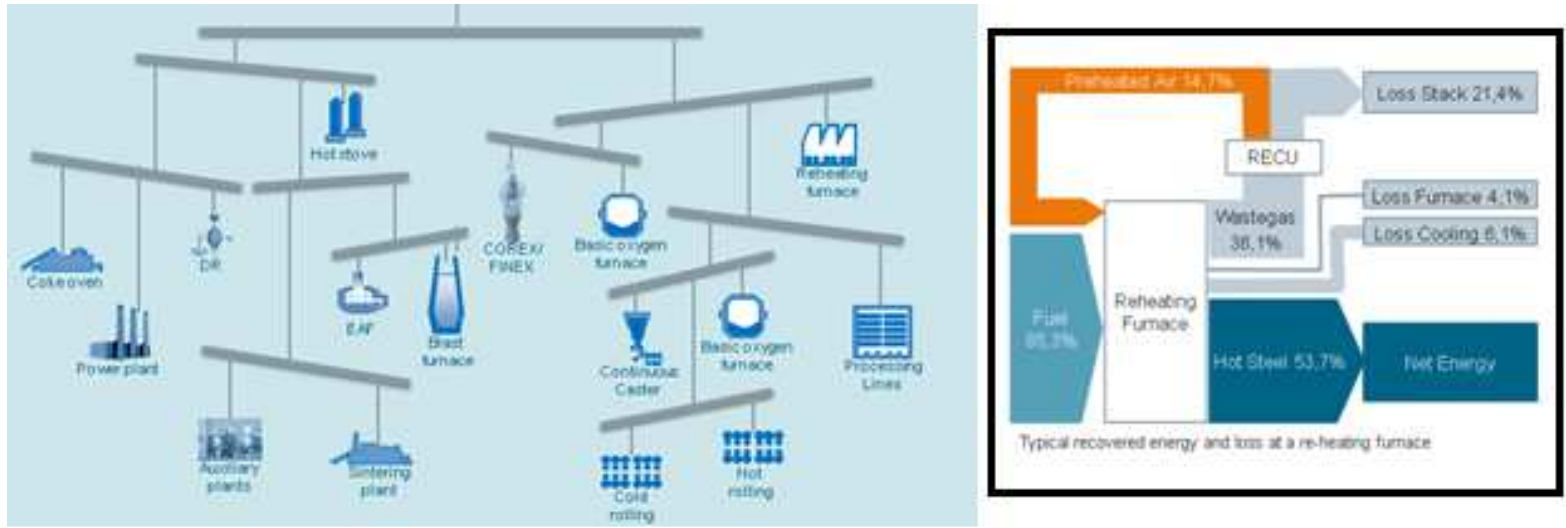

Figura 4 - Identificação de maiores consumidores e oportunidades de melhoria.

- Funções de Verificação:

As funções de verificação englobam as funções de monitoração, medição e analises que são realizadas principalmente por meio da coleta de informações provenientes dos níveis de controle e operação. Dados de consumo de 
energia e diferentes tipos de utilidades são armazenados no nível de controle e operação. No nível de gestão estes dados são então transformados em informações como KPI's, balanços de energia e consumos por centro de custo que permitem uma avaliação da eficiência das medidas para a melhoria de desempenho energético das plantas.

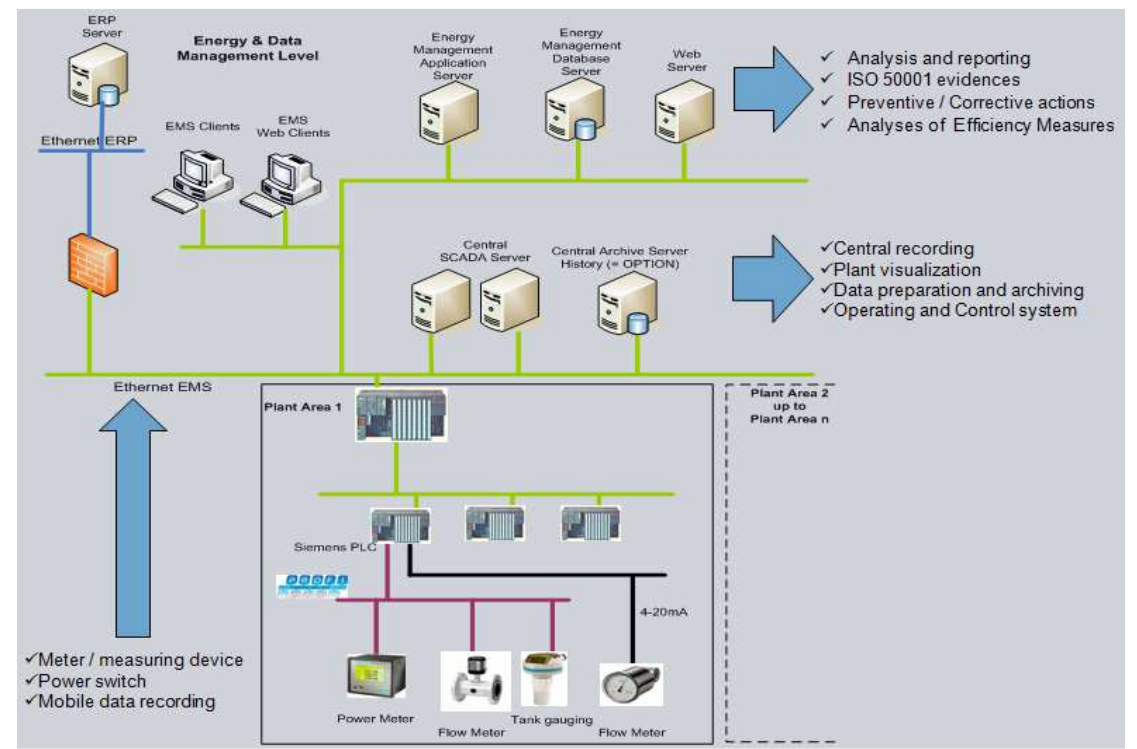

Figura 5 - Funções de Verificação

- Funções de Reporte

As funções de relatórios tem foco no atendimento dos requisitos de auditoria, fornecendo evidencias em relação à conformidade do sistema, avaliação de oportunidades de melhoria da eficiência energética e verificação da sua eficácia. Apoia também o requisito de planejamento energético provendo dados de entrada como, por exemplo: o perfil de consumo no presente e no passado e histórico das variáveis que mais afetam o uso da energia nos processos.
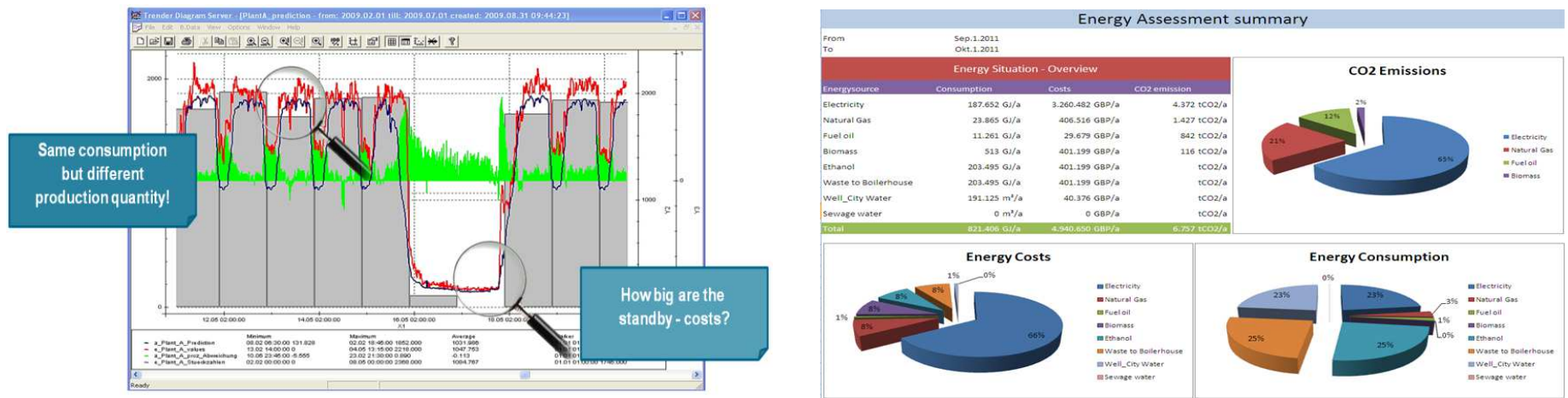

Figura 6 - Relatórios de consumo por planta, tipo de utilidades e emissões de CO2.

A transparência em relação aos consumos permite a correta contabilidade dos gastos e o correto reporte em relação às emissões de $\mathrm{CO} 2$. Em alguns países da Europa existem incentivos, tais como: redução de impostos e subsidio para investimentos à gestão eficiente de energia e controle de emissões, sendo a certificação na norma ISO 50001 um pré-requisito para a obtenção destes benefícios. 

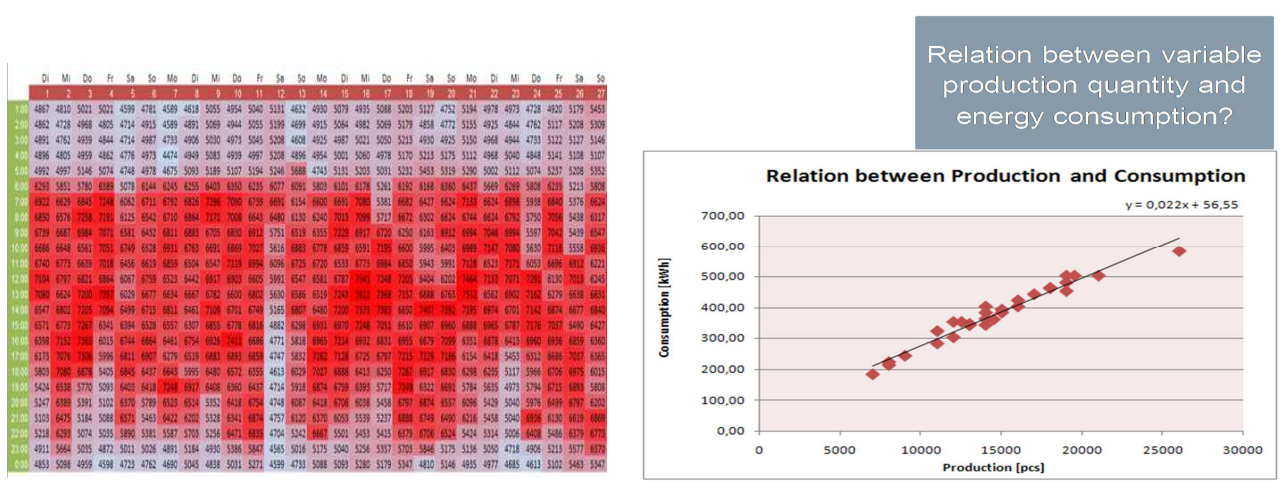

Figura 7 - Relatórios de Consumo X Produção e picos de consumo por dia e hora.

Os relatórios permitem relacionar consumo e produção, assim como avaliar picos de consumo por hora, turno e dia de produção. Estas são variáveis importantes para a previsão de consumo de energia em um período determinado.

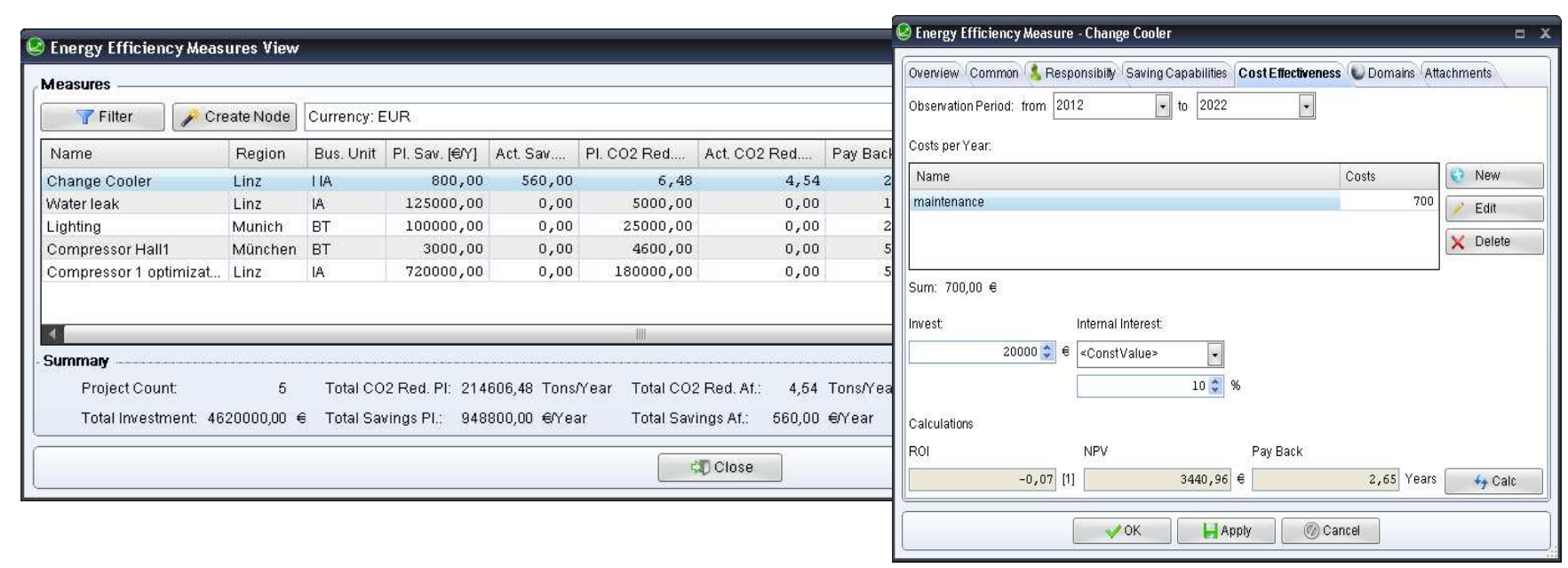

Figura 8 - Relatórios de definição e acompanhamento de medidas de eficiência.

Entre as funções de reporte existe uma ferramenta para o cadastro das medidas de eficiência energética, as quais são identificadas por meio da analise dos processos de revisão energética, e o posterior acompanhamento de resultados para reporte a alta direção.

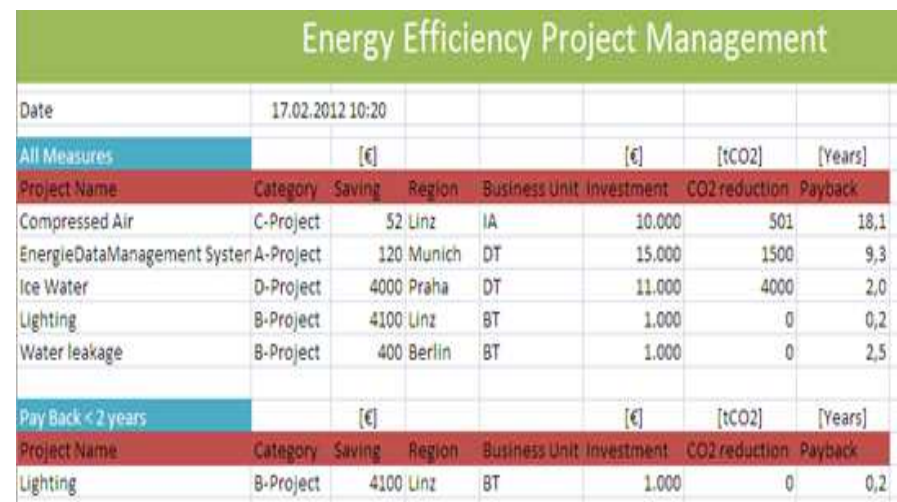

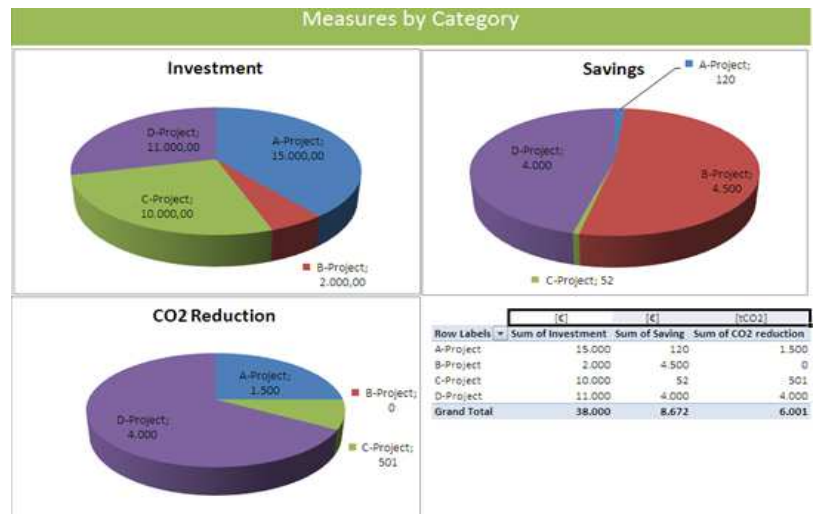

Figura 9 - Status dos Investimentos para reporte a Alta Direção. 
O acompanhamento da eficiência das medidas deve ser monitorado e apresentado periodicamente à alta direção para análise critica dos resultados e para a tomada de decisões relacionadas à melhoria continua do desempenho energético.

\section{RESULTADOS E DISCUSSÃO}

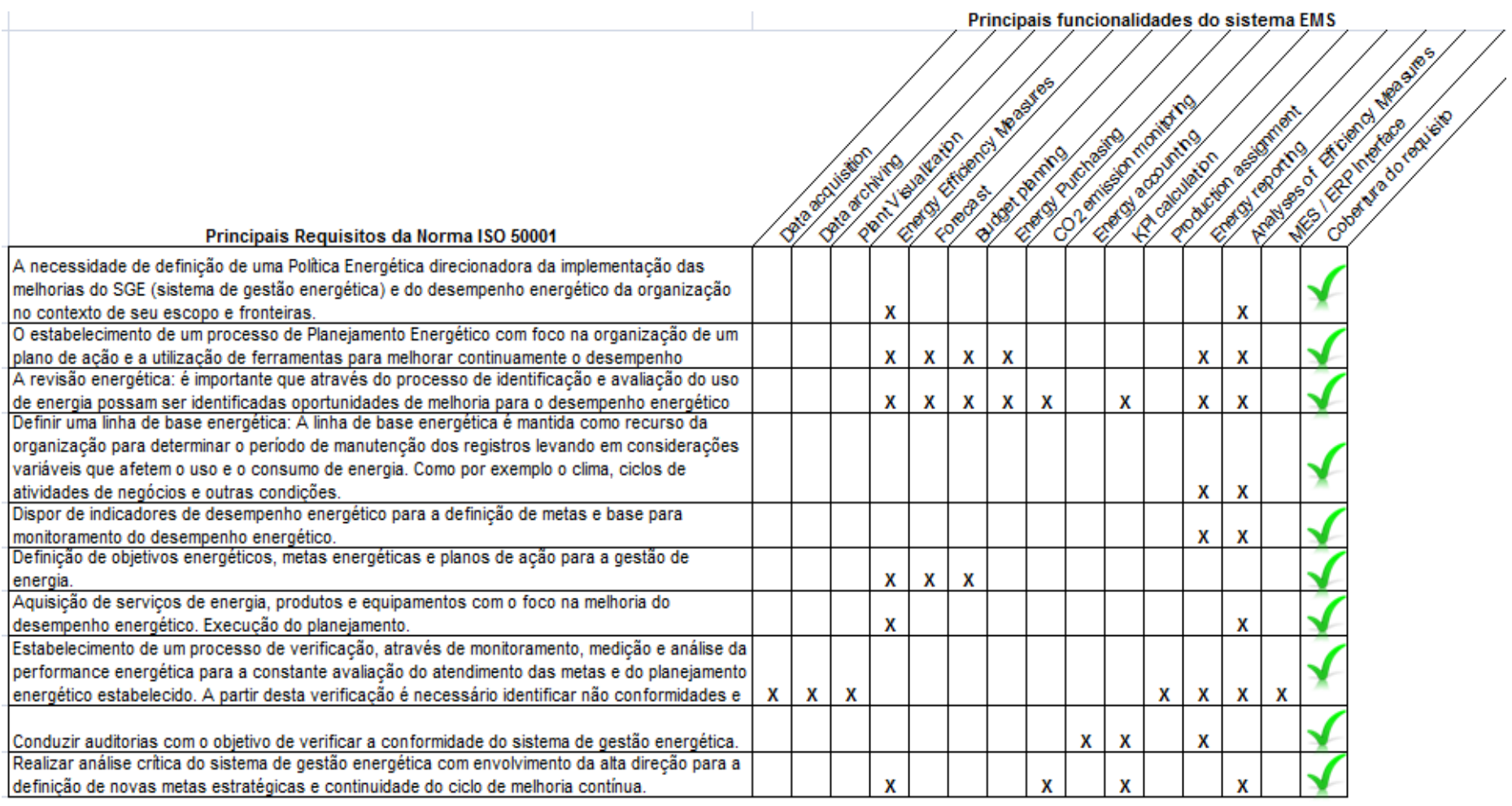

Figura 10 - Matriz de requisitos da norma $X$ cobertura de funcionalidades EMS.

A análise dos requisitos versus funcionalidades apresentam $100 \%$ de aderência do sistema EMS a norma 50001. Desta forma, como resultado pode-se dizer que o sistema EMS com suas camadas de automação e TI industrial, está apto a apoiar a implantação, manutenção e melhoria de sistemas de gestão de energia. Segue abaixo a lista de ganhos potenciais que podem ser obtidos com o atendimento dos requisitos da norma e a implantação do sistema EMS.

- Redução do lançamento manual de informações obtidas no chão de fábrica.

- Maior transparência em relação aos dados de consumo de energia por tipos de utilidades, por área e por planta.

- Previsão do consumo de energia nas próximas, horas, dias e semanas em função do plano de produção.

- Integração de dados de diferentes áreas para comparação e benchmark

- Visualização de KPI's de desempenho energético.

- Identificação de oportunidades de melhoria e acompanhamento de medidas que possam aperfeiçoar o desempenho energético.

- Redução de emissões de $\mathrm{CO}^{2}$ em até $20 \%$ conforme casos de sucesso de outros tipos de indústria.

- Redução do consumo de energia em até $20 \%$ conforme casos de sucesso de outros tipos de indústria.

- Documentação alinhada a requisitos legais e regulatórios. 
Segundo o Plano Nacional de Eficiência Energética elaborado pelo Ministério de Minas e Energia, até 2030 espera-se uma economia no consumo de energia elétrica da ordem de $10 \%$ em relação a uma determinada projeção de demanda baseada em estimativas macroeconômicas de crescimento do PIB. Este planejamento considera ações de eficiência energética que compreendem o progresso autônomo e induzido. Isto significa que além da ação natural de reposição tecnológica por própria iniciativa do mercado (processo autônomo), são também necessários estímulos e políticas públicas que possam induzir novos programas de eficiência energética (processo induzido).

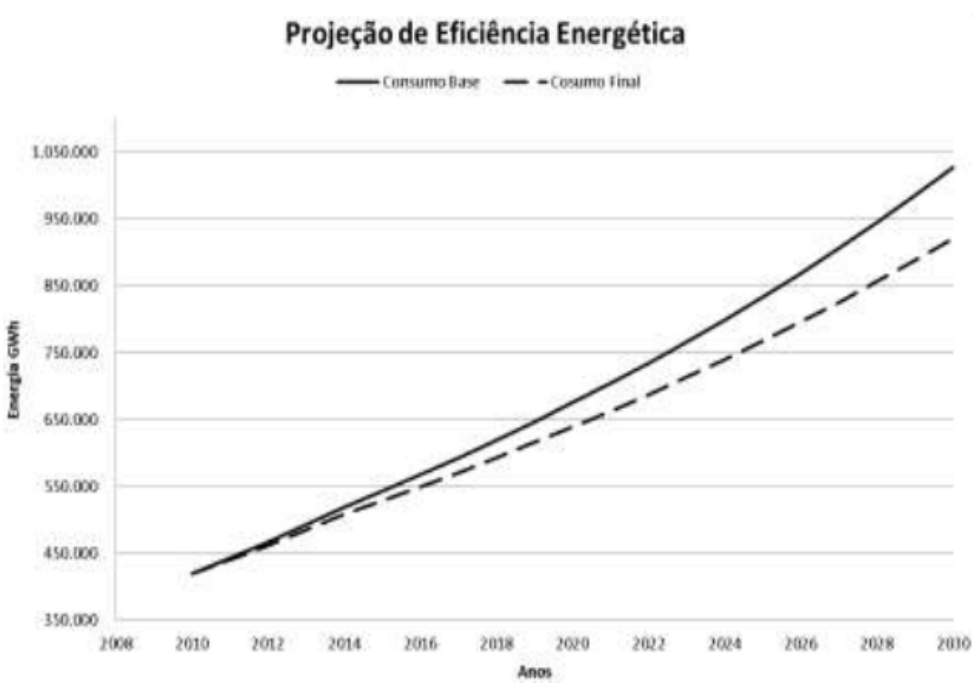

Figura 11 -Projeção de Eficiência Energética.

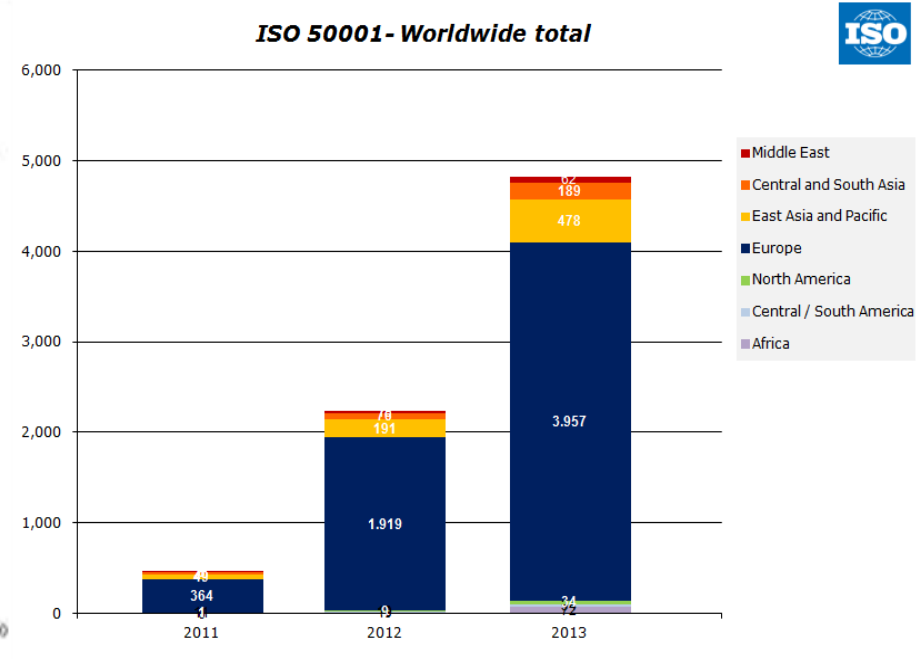

Figura 12- Certificações ISO 50001.

Apesar do setor industrial ser o maior consumidor de energia do país, a maioria das políticas públicas no Brasil tem tido o seu foco nos setores de geração e distribuição de energia. $\mathrm{O}$ que existe de incentivo, são recursos financeiros para estimular à execução de projetos de eficiência energética. Em 2006, o BNDS aprovou o PROESCO, programa que visa a apoiar a execução de projetos que comprovadamente, contribuam para a economia de energia com o foco em iluminação, motores, otimização de processos, produção, automação e controle, estudos, sistemas de informação entre outras ações.

Consoante ao plano de economia previsto até 2030, além de disponibilizar recursos financeiros, ainda é necessário o estabelecimento de um marco legal que busque assegurar a sustentabilidade da Eficiência Energética no Brasil. Para tanto, algumas linhas de ações já aplicadas com sucesso em outros países, principalmente na Europa, podem ser adotadas em breve, como por exemplo: A criação de incentivos fiscais atrelados a medidas de eficiência energética e a definição de requisitos legais baseados em normas e padrões como, por exemplo, a ISO 50001 e ISO 14001.

Segundo o item 3.6 do Plano Nacional de Eficiência Energética, para os setores da Indústria e de Micro, Pequenas e médias Empresas, constam como medidas importantes a serem promovidas: o incentivo de workshops com agentes de financiamento, para apresentar o tema eficiência energética como produto/serviço a ser financiado e em relação a propostas de gestão empresarial, a promoção da criação de comissões internas de conservação de energia nos moldes da ISO 50001, além do estudo da obrigatoriedade da destas comissões para grandes consumidores de energia. O Plano destaca também a necessidade de se fomentar o 
aprimoramento de ferramentas de gestão existentes, incluindo os softwares de gestão energética, para que incorporem os conceitos contidos na norma ISO 50001.

\section{CONCLUSÃo}

- Tendências Mundiais, assim como problemas estruturais no Brasil tem trazido o tema da eficiência energética novamente ao centro das atenções.

- Em relação à gestão de energia, em comparação a outras economias mais desenvolvidas, em especial da Europa, o Brasil se encontra em um patamar inferior por não dispor ainda de políticas claras de incentivo a eficiência energética.

- O Incentivo dado pelo governo através do programa de financiamento PROESCO ainda se mostra pouco conhecido pelas empresas que precisam investir em sistemas de gestão de energia. Desta forma, é necessário promover o tema através de palestras e workshops.

- Em breve poderemos ter a norma ISO 50001 definida como uma base, e eventualmente como um requisito legal e obrigatório para que a Indústria em geral possa melhorar o seu desempenho energético de forma continua.

- O sistema EMS está alinhado à norma ISO 50001 e incorpora conceitos contidos na norma. Conforme mencionado no Plano Nacional de Desenvolvimento é importante fomentar o aprimoramento de ferramentas de gestão alinhadas à norma ISO 50001 para a melhoria do desempenho energético da Indústria.

- Os crescentes custos de energia no Brasil e a grande competição do mercado estão criando uma necessidade imediata de se melhorar o desempenho energético da Indústria de Metais.

- Referências de sucesso de outras soluções baseadas na plataforma SIMATIC B.Data da Siemens implementadas em outras indústrias, assim como diversas implementações da norma ISO 50001 demonstram que existe potencial para que a solução EMS possa ser implementada com sucesso na Indústria de Metais, apoiando de forma sistemática no estabelecimento, manutenção e continuidade de sistemas de gestão para a melhoria contínua do desempenho energético.

\section{BIBLIOGRAFIA}

1 Ministério de Minas e Energia. Plano Nacional de Eficiência Energética [página da internet].[acesso em 14/04/2015]. Disponível em:

http://www.biblioteca.presidencia.gov.br/publicacoes-oficiais-

1/catalogo/conselhos/conselho-nacional-de-politica-energetica/plano-nacional-deeficiencia-energetica-premissas-e-diretrizes-basicas/view

2 Banco Nacional do Desenvolvimento. PROESCO Apoio a projetos de eficiência energética [página da internet].[acesso em 14/04/2015]. Disponível em:

http://www.bndes.gov.br/SiteBNDES/bndes/bndes_pt/Areas_de_Atuacao/Meio_Ambien te/proesco.htm.

3 ABNT Associação Brasileira de Normas Técnicas. NBR ISO $50001: 2011$ 